\title{
Foreign Language Learning Process at an Early Age and Its Impact on the Native Language Education
}

\author{
Shqipe Husaj
}

Prof. ass. Dr., University “Fehmi Agani” Gjakove

\begin{abstract}
Perhaps the most complex question risen among linguists, psychologists and philosophers is how a child learns foreign language? Considering that language learning is natural and that babies are born with the ability to learn it since learning begins at birth, still Language learning (be it native or foreign) is a process that is not simple and short. It takes time, patience and self-discipline. Independent from some internal and external factors that are found inside and outside of every learner and which differ from each and every person this process has its pros and cons. A foreign (English) language learning at an early age has evolved considering modern technologies and methodologies used by individual learners and teachers. The earlier the language is learnt the more fluent the speaker is, but what happens to the mother tongue? Is the child well understood by the community, school teachers and friends? What is the progress of that child at school, what are psychological effects of technology used in the process of learning a language, what is the best age to learn a foreign language? , etc. These and many other questions will be discussed in this paper. The findings of this paper are assumed to also identify teachers' perceptions about the main challenges they face during the classroom management with foreign language speakers in the classroom, the strategies they use, parents' attitude toward this and also to find out some steps that parents and native language teachers should take to improve the situation.
\end{abstract}

Keywords: foreign language, factors, technology, learning, obstacles

\section{Introduction}

In today's world children are surrounded by screens all around them: television sets, computers, tablets, and phones either to watch or play with. And some children even have access to their own tablet and phone, starting at a young age. All these devices help children in a way or another how to behave, learn new games, new languages etc. Children are those who learn a new language quicker and easier as their brain is fresh and has enough space to accumulate things. Language learning through technology has its pros and cons, as its use in an uncontrolled time can harm them a lot without being noticed by their parents.

The earlier the language is learnt the more fluent the speaker is, but what happens to the mother tongue? Is the child well understood by the community, school teachers and friends? What is the progress of that child at school, what are psychological effects of technology used in the process of learning a language, what is the best age to learn a foreign language? , etc. 
But in order to properly discuss the topic of this paper, first we should understand what bilingualism is! Bilingualism refers to the ability to use two languages in everyday life. Bilingualism is common and is on the rise in many parts of the world, with perhaps one in three people being bilingual or multilingual (Wei, 2000). Definitions of bilingualism range from a minimal proficiency in two languages, to an advanced level of proficiency which allows the speaker to function and appear as a native-like speaker of two languages. A person may describe themselves as bilingual but may mean only the ability to converse and communicate orally. Others may be proficient in reading in two or more languages (or bi-literate). A person may be bilingual by virtue of having grown up learning and using two languages simultaneously (simultaneous bilingualism). Or they may become bilingual by learning a second language sometime after their first language. This is known as sequential bilingualism. To be bilingual means different things to different people. ${ }^{1}$

Having a child is a miracle that God blesses every parent, it is a mission given to us to complete in the best way possible. Considering that since the period of pregnancy when the child is in the mother's womb until the age of 6 the child receives what is served to it by the parents / guardians, the family members and the society in general But, not always parent unintentionally manage to do the best. Trying to make them happy parents sometimes do mistakes that will always regret. Or in the contrary, by putting limits on our children we give them lifelong happiness. Early childhood is the most important period of an individual's development and the greatest attention must be paid at this age. The way we feed children, protect them, the way we communicate, socialization, creation of skills and habits, etc. are some of the factors that directly affect their future. Parents, family members and the society that surrounds them are role model and the best lesson on how to behave with themselves and others. Children learn from what they see and experience.

Nowadays, we are witness that almost every child, every young boy or girl, elderly, etc. use a mobile phone as a toy and as a tool to relax and have fun, thus causing Society in general face great difficulties leaving traces in the overall social development. One of the factors that is negatively affecting the development of children is the uncontrolled use of technology especially in early ages.

Doing so very soon they start speaking foreign language, respectively English instead of their mother tongue making their parents proud. The question is: Should the parents really be proud?

The next we seen on those children is wearing glasses.- Should parents worry about this?

Parents themselves do not understand the needs and demands of their children? - Worried about?

Teachers and schoolmates do not completely understand those children and as a result children come home crying for not being understandable because they speak half English half Albanian (in our case- Kosovar children) - What to do?

Bad results at school- Who to blame?

${ }^{1}$ (www.naldic.org.uk/ITTSEAL2/teaching/B1.cfm. 


\section{Methodology, techniques and instruments}

In order to answer all these above mentioned questions and many others, there is a research done with parents, teachers of kindergarten and lower secondary school psychologists by distributing a questionnaire (as an instrument) and observing a class management in 10 schools of Peja, Gjakova and Prishtina municipality.

The questionnaire contains 23 open and close ended questions and comments at the end of it given by each respondent. The research was done in those institutions that are claimed to have pupils/children with such problems.

\section{Research questions}

1. How much will the use of a foreign language in early childhood affect the adequate acquisition of the mother tongue?

2. Will synchronization of foreign language and mother tongue at an early stage increase the confusion of children's expression?

\section{Hypotheses}

$\mathrm{HO}=$ The use of a foreign language in early childhood does not have a major impact on the adequate acquisition of the mother tongue

$\mathrm{H} 1$ = The use of a foreign language in early childhood has a great impact on the adequate acquisition of the mother tongue.

$\mathrm{H} 2$ = Synchronization of foreign language and mother tongue at an early stage greatly increases the confusion of children's expression.

\section{DATA INTERPRETATION}

Model Summary

\begin{tabular}{|l|l|l|l|l|}
\hline \multicolumn{5}{|l|}{ Model Summary } \\
\hline Model & $R$ & $R$ Square & Adjusted R Square & Std. Error of the Estimate \\
\hline 1 & .969 a & .947 & .931 & .256 \\
\hline $\begin{array}{l}\text { Children who speak foreign language vs. those who do not speak foreign language. Development of competencies. } \\
\text { Advantages of foreign language. Intelligence of children who speak two languages }\end{array}$
\end{tabular}

The Model Summary table shows how well independent variables (Children who speak a foreign language vs. those who do not speak a foreign language, Competence development, Foreign language advantages, Intelligence of bilingual children) explain the dependent variable : Acquisition of mother tongue. In this case it is said that R2 is $0.947 \times 100=94.7 \%$ the independent variables explain the dependent variable.

Coefficients ${ }^{a}$

\begin{tabular}{|c|c|c|c|c|c|}
\hline \multirow[t]{2}{*}{ Model } & \multicolumn{2}{|c|}{ Unstandardized Coefficients } & Standardized & \multirow[t]{2}{*}{$t$} & \multirow[t]{2}{*}{ Sig. } \\
\hline & $B$ & Std. Error & Beta & & \\
\hline (Constant) & .418 & .668 & & .627 & .558 \\
\hline $\begin{array}{l}\text { Children speaking a foreign language } \\
\text { vs. those who do not }\end{array}$ & 622 & .398 & .593 & 2.662 & .002 \\
\hline
\end{tabular}




\begin{tabular}{|l|l|l|l|l|l|} 
Competence development & .105 & .674 & .089 & 2.156 & .012 \\
Advantages of a foreign language & .412 & .359 & .480 & 2.870 & .002 \\
The ingenuity of bilingualism & .206 & .442 & .188 & 4.467 & .000 \\
\hline
\end{tabular}

Dependent Variable: Acquisition of a foreign language

The results on the above table show that all independent variables have a significance level lower than $0.05 \%$. Then based on this we say that Hypothesis zero (H0) is rejected and the alternative Hypothesis (H1) is accepted. The interpretation of this hypothesis is: The use of a foreign language in early childhood has a great impact on the adequate acquisition of the mother tongue

Correlations

\begin{tabular}{|ll|l|l|}
\hline & & $\begin{array}{l}\text { Thinking Confusion } \\
\text { of bilingual children }\end{array}$ & $\begin{array}{l}\text { Fighting bilingualism } \\
\text { in the context of } \\
\text { children at an early } \\
\text { stage }\end{array}$ \\
\hline $\begin{array}{lll}\text { Thinking Confusion of bilingual } \\
\text { children }\end{array}$ & $\begin{array}{l}\text { Pearson Correlation } \\
\text { Sig. (2-tailed) }\end{array}$ & 1 & $.957^{* *}$ \\
Fighting bilingualism in the context of & $N$ & .000 \\
children at an early stage & Pearson Correlation & 10 & 10 \\
& Sig. (2-tailed) & $.957^{* *}$ & 1 \\
& $N$ & .000 & 10 \\
\hline
\end{tabular}

**. Correlation is significant at the 0.01 level (2-tailed).

${ }^{* *}$ Correlation is significant at the 0.05 level (2-tailed).

The correlation table gives us a mathematical value to measure the strength of the linear correlation between two variables. As it can be seen on the table the correlation coefficient concludes a positive correlation between: Thinking Confusion of bilingual children and Fighting bilingualism in the context of children at an early stage, and we can say that this correlation is at a significance level $0.05(0.000)$

Based on the research question: Will synchronization of foreign language and mother tongue at an early stage increase the confusion of children's expression? The results on the table with a significance lower than $0.05(0.000)$, the interpretation of the hypothesis (H2) would be: Synchronization of foreign language and mother tongue at an early stage greatly increases children's confusion of expression.

\section{Conclusion}

In this article it was tried hard to analyze the use of technology in early childhood and its impact on native education process. The research was run in some preschool institution having children who speak a foreign language. Their teachers shared their experience with us on pros and cons of technology use in early childhood.

We also consulted different books such as The Bilingual Edge (King \& Mackey, 2009), and articles such as The Power of the Bilingual Brain (TIME Magazine; Kluger, 2013) that have touted the potential benefits of early bilingualism. According to these and many other resources one of the most important benefits of early bilingualism is often taken for granted: bilingual children will know multiple languages, which is important for travel, employment, speaking with members of one's extended family, maintaining a connection to family culture and history, and making friends from different backgrounds. However, beyond obvious 
linguistic benefits, our research has shown that parents need to realize the importance of teaching their child to play and limit the use of technology.

Even though the science of bilingualism is still a new field, and definitive answers to many questions are not yet available, researchers are doing their best to rise parents' awareness on the pros and cons of technology use in early childhood. Our research concluded that:

Despite the fact that the use of technology develops child's communication skills, develops intelligence, increases self-esteem and self-confidence, by giving the opportunity to become bilinguals, bilingual children are more likely to have language difficulties, delays, or disorders. Therefore parents are advised to introduce the second language and the use of technology after they have mastered their mother tongue fluently.

Technology use makes children confused as they mix words from two languages in the same sentence which is known as code mixing. Therefor this makes them misunderstood. According to Pearson, 2008, code mixing is a normal part of bilingual development, as they are doing exactly what they hear on their technology devices .

Technology use makes children smarter as they will learn multiple languages, which is important for travel, employment, speaking with members of one's extended family, maintaining a connection to family culture and history, and making friends from different backgrounds. ; Technology fosters open-mindedness, offers different perspectives on life, and reduces cultural ignorance; it also gives you more job opportunities and greater social mobility

\section{References}

[1] Bialystok, E., Craik, F. I., \& Luk, G. (2012). Bilingualism: consequences for mind and brain. Trends in Cognitive Sciences, 16(4), 240-250.

[2] Carlson, S. M., \& Meltzoff, A. N. (2008). Bilingual experience and executive functioning in young children. Developmental Science, 11(2), 282-298.

[3] Fan, S. P., Liberman, Z., Keysar, B., \& Kinzler, K. D. (2015). The Exposure Advantage: Early Exposure to a Multilingual Environment Promotes Effective Communication. Psychological Science, 26(7), 1090-1097.

[4] Morales, J., Calvo, A., \& Bialystok, E. (2013). Working memory development in monolingual and bilingual children. Journal of Experimental Child Psychology, 114(2), 187-202.

[5] Grosjean, F. Attitudes and feelings about bilingualism. Chapter 9 of Grosjean, F. (2010). Bilingual: Life and Reality. Cambridge, Mass: Harvard University Press.

[6] Preston, P. (1995). Mother Father Deaf. Cambridge, MA: Harvard University Press.

[7] "Life as a bilingual" posts by content area: http://www.francoisgrosjean.ch/blog_en.html

[8] François Grosjean's website: www.francoisgrosjean.ch 